\title{
Preliminary results of a counselling programme for fertility preservation in female cancer patients: The experience of the GEMME DORMIENTI network
}

\author{
Mariavita Ciccarone ${ }^{1,2}$ (D) | Stefan Hohaus ${ }^{3}$ | Alessandro Pulsoni ${ }^{4}$ | Paola Cavaceppi ${ }^{5}$ \\ Simona Franzò $^{2}$ | Raffaella Fabbri $^{6}$ | Laura Cudillo ${ }^{7}$ | Roberta Battistini ${ }^{8}$ | \\ Alice Di Rocco ${ }^{4}$ | Ombretta Annibali ${ }^{9}$ | Maria Christina Cox ${ }^{10}$ | Ida Provenzano ${ }^{11}$ | \\ Elisabetta Abruzzese $^{12}$ | Daniela Renzi ${ }^{13}$ | Cristiano Tesei ${ }^{2}$ | Paola Anticoli Borza ${ }^{14}$ | \\ Annarosa Cuccaro $^{3}$ | Alessandro Andriani ${ }^{15,16}$ | Gianna Maria D'Elia ${ }^{4}$ | \\ Antonio Facchiano $^{17}$ | Paolo Marchetti ${ }^{18}$ | Maria Cantonetti ${ }^{11}$
}

${ }^{1}$ Department of Gynaecology, San Carlo di Nancy Hospital, Rome, Italy

${ }^{2}$ Gemme Dormienti Association ONLUS,

Rome, Italy

${ }^{3}$ Policlinico Gemelli Foundation, Catholic University of the Sacred Heart, Rome, Italy

${ }^{4}$ Department of Cellular Biotechnology and Haematology, Sapienza University, Rome, Italy

${ }^{5}$ LabAurelia, Rome, Italy

${ }^{6} \mathrm{Gynaecology}$ and Physiopathology of Human Reproduction Unit, Department of Medical and Surgical Sciences, S.OrsolaMalpighi Hospital, University of Bologna, Bologna, Italy

${ }^{7}$ Haematology and Stem Cell Transplant Unit, Tor Vergata University, Roma, Italy

${ }^{8}$ A.O. San Camillo Forlanini U.O.C. Ematologia e Trapianti CSE, Rome, Italy

${ }^{9}$ UOC Haematology Stem Cell

Transplantation, University Campus Bio

Medico, Rome, Italy

${ }^{10}$ Haematology Unit, Azienda OspedalieraUniversitaria Sant'Andrea, Rome, Italy

${ }^{11}$ UOC Oncoematologia Fondazione Policlinico Tor Vergata, Rome, Italy

${ }^{12}$ Ematologia Ospedale S. Eugenio Università Tor Vergata, Rome, Italy

${ }^{13}$ Haematology and Stem Cell Transplant Unit, IRCCS Regina Elena National Cancer Institute, Rome, Italy

${ }^{14}$ UOC Ematologia- Azienda Ospedaliera San Giovanni-Addolorata, Rome, Italy

${ }^{15}$ UOSD di Ematologia, Rome, Italy

\begin{abstract}
Objective: To describe a population of patients referred for fertility preservation (FP), how to efficiently provide FP care, and how FP care changed over time.

Methods: This longitudinal observational study enrolled 281 female cancer patients referred between 2013 and 2016 to the non-profit organisation Gemme Dormienti ONLUS (GD) for FP care. All patients underwent the same battery of instrumental and laboratory diagnostic tests. GnRHa therapy was started at least seven days before CTh treatment.

Results: From 2013 to 2016, we observed a progressive increase in the number of patients referred for FP care. Out of 251 eligible patients, 135 patients were treated with GnRHa only, and 72 patients underwent GnRHa therapy and cryopreservation. The median time from GD referral to oocyte and ovarian tissue cryopreservation was 11 and 5 days respectively. Tissue cryopreservation requests increased during our study period (from four cases in 2013 to 17 cases in 2016). During follow-up, 17 $\beta$-estradiol and FSH levels were significantly increased $(p<.0001)$, and AMH levels were significantly decreased $(p<.0001)$.

Conclusion: The rapid increase in the number of patients who requested FP care and in the complexity of FP procedures overtime reflects the need to improve quality of life for cancer patients.
\end{abstract}

\section{KEYWORDS}

cancer, counselling, fertility preservation, $\mathrm{GnRHa}$, oocyte cryopreservation, ovarian tissue cryopreservation 
${ }^{16}$ UOC di Ematologia, Osp. F. Spaziani, ASL

Frosinone, Rome, Italy

${ }^{17}$ Department of Medical Oncology Sant'

Andrea Hospital, Rome, Italy

${ }^{18}$ Department of Radiological, Oncological and Pathological Sciences, Sapienza

University, Rome, Italy

\section{Correspondence}

Mariavita Ciccarone, Gemme Dormienti Association ONLUS, Via Cesare Balbo $n^{\circ} 4$, Rome, Italy.

Email: mariavita.ciccarone@

gemmedormienti.it

Funding information

OPM (Otto Per Mille) Chiesa Evangelica

Valdese

\section{1 | INTRODUCTION}

The remarkable prolongation of survival seen in younger cancer patients in the past decades (Siegel, Miller, \& Jemal, 2017) has shed light on the long-term side effects of anti-cancer therapies. Among these, temporary or permanent fertility impairment (Gracia et al., 2012; Stensheim, Cvancarova, Møller, \& Fosså, 2011) raises concerns for reproductive-age patients facing gonadotoxic therapies, causing psychological distress and possibly affecting treatment decision (Lawson et al., 2014; Partridge et al., 2004; Ruddy et al., 2014). Hence, fertility preservation (FP) care has become paramount in this complex setting. Several strategies are currently available, including ovarian suppression through gonadotropin-releasing hormone agonists ( $\mathrm{GnRHa}$ ) and cryopreservation of oocytes as well as ovarian tissue. The use of $\mathrm{GnRHa}$ during chemotherapy (CTh) is an attractive option to preserve both ovarian function and fertility, with the advantage of avoiding delays in cancer treatment (Lambertini, Ginsburg, \& Partridge, 2015). Compelling evidence supports the benefit yielded by $\mathrm{GnRHa}$ administration in cancer patients in terms of reduced risk of CTh-induced premature ovarian failure (POF) (Del Mastro et al., 2011, 2014; Lambertini et al., 2014; Lambertini, Ceppi, et al., 2015; Moore et al., 2015) and increased pregnancy rates (Del Mastro et al., 2011; Lambertini, Ceppi, et al., 2015; Matteo Lambertini et al., 2014, 2017; Moore et al., 2015; Wong, O'Neill, Walsh, \& Smith, 2013), with no negative impact on prognosis (Lambertini, Ceppi, et al., 2015). Despite the efficacy of this option in some cancer types, GnRHa remains controversial (Behringer et al., 2012; Blumenfeld, Zur, \& Dann, 2015; Demeestere et al., 2016; Tavares, Senra, Talim, \& Reis, 2016). While a protective effect has been demonstrated in breast cancer patients (Del Mastro et al., 2011, Del Mastro et al., 2014, Blumenfeld et al., 2015, Blumenfeld \& Evron, 2016), more studies are needed to confirm the protective role of $\mathrm{GnRHa}$ in patients with other types of cancer (Demeestere et al., 2016, reviewed in Lambertini, Horicks, Mastro, Partridge, \& Demeestere, 2019). The Italian Association of Medical Oncology (AIOM) has recently issued a strong positive recommendation to adopt the use of $\mathrm{GnRHa}$ for both ovarian function and FP in cancer patients (Lambertini et al., 2017). We believe that the use of $\mathrm{GnRHa}$ is useful in preserving fertility regardless of the type of tumour (Blumenfeld \& Evron, 2016; Garrido-Oyarzun \& Castelo-Branco, 2016; Lambertini et al., 2019).

Oocyte cryopreservation is now considered a standard FP option (Practice Committee of American Society for Reproductive Medicine, 2013). However, it requires controlled ovarian stimulation (COS), which may delay CTh and affect the prognosis of patients with hormone-responsive tumours (Lambertini et al., 2016). To overcome this problem, alternative approaches have been developed, either to avoid COS (i.e. cryopreservation of immature oocytes or of oocytes matured in vitro [Cao \& Chian, 2009; Oktay et al., 2008]) or to start it at any time (i.e. random start protocol that requires $\geq 2$ weeks of treatment [Cakmak \& Rosen, 2013]).

Ovarian tissue cryopreservation has been proven to be effective for the recovery of ovarian function, but remains an experimental procedure (Lambertini et al., 2016; Practice Committee of American Society for Reproductive Medicine, 2013). Tissue cryopreservation may be performed at any time during the menstrual cycle without COS and is currently the only option for pre-pubertal girls facing gonadotoxic therapies. Moreover, it is suitable for patients who cannot delay CTh initiation, who have already received a few cycles of low gonadotoxic risk CTh or have contraindications to COS. However, tissue cryopreservation is generally suitable for women aged $<35$ years, and the success of the procedure depends on ovarian reserve (Matteo Lambertini et al., 2016). Currently, in vitro maturation techniques are under investigation to prevent the risk of malignant cell re-implantation associated with this technique (Blumenfeld, 2016; Salama, Isachenko, Isachenko, Rahimi, \& Mallmann, 2016).

Several international guidelines recommend physicians to promptly and comprehensively inform patients facing gonadotoxic treatment about the risks of fertility impairment and the possibility of FP and to support them throughout the decision-making process (AIOM, 2016; ISFP Practice Committee et al., 2012; Loren et al., 2013; 
Peccatori et al., 2013; Practice Committee of American Society for Reproductive Medicine, 2013). Both physicians and patients have acknowledged the importance of offering oncofertility counselling and having multidisciplinary teams (MDT) that establish individualised approaches based on the patient's characteristics. Despite the reported physical and psychological benefits and improved quality of life (QoL) in patients undergoing FP care (Deshpande, Braun, \& Meyer, 2015; Razzano et al., 2014), FP counselling and procedures are not routinely implemented as part of patient care (Diesch et al., 2017).

Nonetheless, the increasing rate of referrals to FP centres and of FP procedures performed reflects the efforts to improve patient care in this complex and rapidly evolving setting (Sigismondi et al., 2015; Vu, Llarena, Estevez, Moravek, \& Jeruss, 2017).

The Gemme Dormienti (GD) ONLUS is an Italian non-profit association established in 2011 by experienced physicians willing to provide free professional support for women coping with gonadotoxic treatment, due to cancer or other conditions, and severe impairment of QoL. By supporting these patients throughout the process of FP, GD aims at restoring their ovarian function and increasing their chances of pregnancy.

In this study, we characterise the population of patients referred to GD for FP care, how these patients were managed, and how FP care changed over time.

\section{2 | METHODS}

\section{1 | Study design}

This is an observational, single-centre study documenting the strategy of FP care given to female cancer patients of reproductive age, referred to GD between 01/01/2013 and 31/12/2016.

We collected data on the main demographic and clinical characteristics of cancer patients (the ones affected by other pathologic conditions were excluded), past and planned therapies, and FP strategy adopted. A sample size calculation was not carried out because we performed an observational study in which all eligible patients who were referred to our centre during the study period were enrolled.

\subsection{Patient population}

Patients were included if post-pubertal, aged $<45$ years and if they had a diagnosis of cancer requiring gonadotoxic treatment. All of them were eligible for treatment with GnRHa. Patients were eligible for cryopreservation if aged $\leq 38$ years, and if they had not previously received high-risk CTh or HSCT. Exclusion criteria were a poor prognosis quoad vitam and histologically or cytologically confirmed ovarian metastases.

All patients referred to GD provided signed informed consent. For patients aged $<18$, the consent was signed by the legal tutor. Study approval was obtained by the Ethics Committee of IDI IRCCS (Istituto Dermopatico dell'Immacolata-Istituto di Ricovero e Cura a
Carattere Scientifico) Prot. n. 45/CE/2017. The study was conducted in accordance with the Declaration of Helsinki.

\section{3 | Oncofertility programme}

The oncofertility programme developed by GD aims to provide patients with comprehensive FP counselling and screening of ovarian function, supporting them in the decision-making process, and taking appropriate measures to avoid delays in cancer treatment. The GD's programme relies on a network of oncologists, oncohaematologists and paediatric centres from hospitals and universities across Italy. Upon diagnosis of cancer, healthcare providers can schedule an appointment at GD within 24-48 hr through a dedicated phone number to ensure rapid access to the FP programme. During the medical appointment at GD, a gynaecological examination is carried out, medical (physiological, family, gynaecological and cancer) history is taken, and the treatment plan is carefully revised.

Through a centralised laboratory that manages to provide results within $6 \mathrm{hr}$, the following assessments are carried out: hormonal profile (follicle-stimulating hormone [FSH], luteinizing hormone [LH], $17 \beta$-estradiol $[17 \beta \mathrm{e}]$, progesterone, prolactin, thyroid-stimulating hormone [TSH], and anti-müllerian hormone [AMH]), Pap-test, pelvic ultrasound scan with antral follicle count (AFC) and endometrial thickness. These exams are the standard of care outlined by AIOM guidelines for FP in cancer patients. The strength of the FP programme developed by GD is to complete the whole assessment on the same day: due to time constraints, blood samples for hormonal profiling are collected randomly.

Patients $>18$ years were requested to fill a questionnaire to assess their psychological status and motivation to pursue FP. They were offered counselling throughout the entire treatment period and during follow-up if needed. Patients were given follow-up examinations 1, 6, 12, 24 and 36 months after completion of CTh. Further follow-up appointments were scheduled according to the patients' availability.

\subsection{Fertility preservation techniques}

The options adopted by GD to preserve fertility are chemoprevention with $\mathrm{GnRHa}$ and/or cryopreservation of oocytes and/or ovarian tissue.

All post-pubertal patients $<45$ years received $\mathrm{GnRHa}$, which is reimbursed by the Italian healthcare system since July 2016, regardless of the type of tumour. The decision for cryopreservation was made based on patient's age, treatment plan and ovarian reserve at baseline. Eligible patients willing to undergo the procedure were referred to public centres of excellence in Italy. According to the programme, GnRHa therapy was started at least 7 days before CTh treatment, to avoid chemotherapy during the expected ovarian flare-up that follows GnRHa administration. The time frame between the first GD examination, FP procedures and the start of chemotherapy was of 7-10 days in the case of ovarian tissue preservation, and 3 weeks 


\begin{tabular}{|c|c|c|c|c|c|}
\hline \multirow[b]{2}{*}{ Characteristics } & \multirow{2}{*}{$\begin{array}{l}\text { All } \\
N=251\end{array}$} & \multirow{2}{*}{$\begin{array}{l}\text { GnRHa } \\
N=135\end{array}$} & \multicolumn{2}{|c|}{ GnRHa + Cryo } & \multirow{2}{*}{$\begin{array}{l}\text { No FP } \\
N=44\end{array}$} \\
\hline & & & $\begin{array}{l}\text { Oocytes } \\
N=31\end{array}$ & $\begin{array}{l}\text { Tissue } \\
N=41\end{array}$ & \\
\hline Age, years & $31(3-44)$ & $31(18-44)$ & $30(17-38)$ & $24(3-33)$ & $38(14-44)$ \\
\hline \multicolumn{6}{|l|}{ Parity (na = 1) } \\
\hline 0 & $190(76)$ & $94(69.6)$ & $27(90)$ & $37(90.2)$ & $32(72.7)$ \\
\hline 1 & $35(14)$ & $25(18.5)$ & $3(10)$ & $2(4.9)$ & $5(11.4)$ \\
\hline $2-5$ & $25(10)$ & $16(11.9)$ & $0(0)$ & $2(4.9)$ & 7 (15.9) \\
\hline \multicolumn{6}{|l|}{ Education ( $\mathrm{na}=40$ ) } \\
\hline Secondary school & $25(11.8)$ & $14(12.1)$ & $1(3.8)$ & $6(17.6)$ & 4 (11.4) \\
\hline High school & $110(52.1)$ & $65(56)$ & $9(34.6)$ & $20(58.8)$ & $16(45.7)$ \\
\hline Degree & $76(36)$ & 37 (31.9) & $16(61.5)$ & $8(23.5)$ & $15(42.9)$ \\
\hline \multicolumn{6}{|l|}{ Occupation $(n a=44)$} \\
\hline $\begin{array}{c}\text { Housekeeper/ } \\
\text { unemployed }\end{array}$ & $9(4.3)$ & $3(2.6)$ & $1(3.7)$ & $2(6.5)$ & $3(8.8)$ \\
\hline Student & $55(26.6)$ & 27 (23.3) & $8(29.6)$ & $15(48.4)$ & $6(17.6)$ \\
\hline $\begin{array}{l}\text { Craft workers and } \\
\text { others }\end{array}$ & $39(18.8)$ & $24(20.7)$ & $5(18.5)$ & $4(12.9)$ & $6(17.6)$ \\
\hline Professionals & $104(50.2)$ & $62(53.4)$ & $13(48.1)$ & $10(32.3)$ & $19(55.9)$ \\
\hline \multicolumn{6}{|l|}{ Cancer type } \\
\hline $\mathrm{HL}$ & $118(47)$ & $65(48.1)$ & $15(48.4)$ & $26(63.4)$ & $12(27.3)$ \\
\hline $\mathrm{NHL}$ & $53(21.1)$ & $32(23.7)$ & $5(16.1)$ & $5(12.2)$ & $11(25)$ \\
\hline Breast cancer & $37(14.7)$ & $19(14.1)$ & $8(25.8)$ & $2(4.9)$ & 8 (18.2) \\
\hline Leukaemia & $21(8.4)$ & $13(9.6)$ & $2(6.5)$ & $2(4.9)$ & $4(9.1)$ \\
\hline $\begin{array}{l}\text { Other solid/hema- } \\
\text { tol. malignancies }\end{array}$ & $22(8.8)$ & $6(4.4)$ & $1(3.2)$ & $6(14.6)$ & $9(20.5)$ \\
\hline \multicolumn{6}{|l|}{ First-line therapy } \\
\hline $\mathrm{RT}(\mathrm{na}=2)$ & $101(21.4)$ & $57(21.1)$ & $12(21.8)$ & $16(19.3)$ & $16(24.6)$ \\
\hline CTh $(\mathrm{na}=12)$ & $227(48)$ & $129(47.8)$ & $24(43.6)$ & $39(47)$ & $35(53.8)$ \\
\hline$A B V D$ & $116(24.5)$ & $63(23.3)$ & $15(27.3)$ & $26(31.3)$ & $12(18.5)$ \\
\hline $\mathrm{CHOP}$ & $29(6.1)$ & $21(7.8)$ & $4(7.3)$ & $2(2.4)$ & $2(3.1)$ \\
\hline
\end{tabular}

TABLE 1 Demographic and clinical characteristics of female cancer patients deemed as adequate for fertility preservation, at the time of first referral to Gemme Dormienti

Note: Data are expressed as median (range) or frequency ( $[\%])$.

Abbreviations: ABVD, doxorubicin, bleomycin, vinblastine, dacarbazine; $\mathrm{CHOP}$, cyclophosphamide, doxorubicin, vincristine, prednisolone; Cryo, cryopreservation; CTh, chemotherapy; GD, Gemme Dormienti Onlus; GnRHa, gonadotropin-releasing hormone agonist;; HL, Hodgkin lymphoma; na, not available; NHL, non-Hodgkin lymphoma; RT, radiotherapy.

in the case of oocyte pick-up, due to the need for COS (Oktay et al., 2008). Usually, two weeks are enough to perform COS. RANDOM START protocols-which allow stimulation to start immediately, regardless of the phase of the cycle in which the patient is-have been proposed to avoid long waiting times and treatment delays (Allen et al., 2018; Moravek et al., 2018). If the patient is referred immediately to GD's for FP (while she is doing the tests for the diagnosis and staging of her disease, as per protocol), the delay is minimal and of no influence on disease outcome (Allen et al., 2018 and Moravek et al., 2018). For patients affected by Hodgkin's lymphoma, tissue cryopreservation laparoscopy could be performed after the second ABVD cycle if an early restaging showed a poor response or, in case of relapse, before the salvage therapy, generally consisting in highdose chemotherapy (HD-CTh) and autologous stem cell transplantation (ASCT).

\section{5 | Statistical analysis}

Patients' characteristics were summarised by means of frequency $(n)$ and percentage (\%) for categorical variables or by means of $n$ min q1 median q3 max for continuous variables.

Boxplots were used to show $\mathrm{AMH}, \mathrm{FSH}$ and $17 \mathrm{Be} 2$ values during the follow-up visits. Differences among groups were evaluated in univariate analysis by means of non-parametric tests (chi-squared 
and Fisher's exact test in case of categorical variables or response rate, Mann-Whitney and Kruskal-Wallis test in case of continuous variables). Confidence intervals were estimated at $95 \%$ level, and all tests were two-sided, accepting $p<.05$ as indicating a statistically significant difference. All analyses were performed using the SAS system (version 9.4) and R software.

\section{3 | RESULTS}

\section{1 | Patient population and FP}

From 2013 to 2016, we screened a group of 281 female patients. Out of these, 30 (10.7\%) patients were affected by non-neoplastic chronic conditions (multiple sclerosis, rheumatoid arthritis, Behçet's syndrome, thalassaemia major, Myelodysplastic syndrome, aplastic anaemia, among others), did not fulfil the inclusion criteria and were therefore excluded from the study. The remaining 251 (89.3\%) were cancer patients, aged $<45$ years, and deemed eligible for FP with the following diagnosis: Hodgkin lymphoma (HL, $n=118,47 \%$ ), non-Hodgkin lymphoma (NHL, $n=53,26.6 \%$ ), breast cancer $(n=37$, $14.7 \%$ ), leukaemia ( $n=21,8.4 \%$ ), other solid and haematologic malignancies ( $n=22,8.8 \%)$.

The main demographic and clinical characteristics of the population are shown in Table 1 according to the fertility strategies adopted. At the time of the first referral to GD, the median age of all patients was 31 years (range: $3-44)$. In the three FP groups (GnRHa, $\mathrm{GnRHa}$ and oocyte cryopreservation, and GnRHa and ovarian tissue cryopreservation), median age was 31 years (range: 18-44), 30 years (17-38) and 24 years (range: $3-33$ ) respectively. The median age of patients was significantly higher in the group not undergoing FP than in the other groups (38 years, range: $14-44, p<.0001$ ).

In the GnRHa group, ovarian suppression was achieved by administration of leuprorelin acetate in 112 patients (83.0\%) and triptorelin in 18 (13.3\%). Five patients (3.7\%) chose to continue taking the contraceptive pill they were already on to avoid GnRHa adverse effects.

Among these, patients were considered eligible for cryopreservation if they were aged $\leq 38$ years, had a good prognosis quoad vitam, no sign of ovarian metastases and no previous administration of high-risk CTh or autologous HSCT (haematologic stem cell transplant).

The chemoprevention approach alone was employed in 135 patients (65.2\%), whereas 41 (19.8\%) underwent GnRHa treatment and ovarian tissue cryopreservation. Thirty-one patients (15.0\%) were treated with $\mathrm{GnRHa}$ and performed oocyte cryopreservation (Table 1). One patient included in the GnRHa, and tissue cryopreservation group underwent also oocyte cryopreservation. In the GnRHa only group ( $n=135)$, cryopreservation was not performed in 12 patients ( $8.89 \%$ ) because they were over the age limit ( $>38$ years old). In the remaining 123 age-eligible patients, cryopreservation was not performed for several reasons: personal choice $(n=42$, $31.11 \%)$, referral after high-risk CTh or HSCT ( $n=39,28.89 \%)$, lack of cryopreservation indication as they had to undergo low-risk CTh
( $n=21,15.56 \%)$, not being able to postpone CTh ( $n=17,12.59 \%)$, and surgical contraindication due to medical conditions ( $n=4$, 2.96\%).

A total of 24 patients were treated between 2013 and 2016 with oocyte stimulation (mean oocytes taken: 9 [1-33]). Out of 24 patients, 2 (8.3\%) had an adverse event (ovarian hyperstimulation syndrome). In both cases, the adverse event was resolved according to the guidelines with case-specific therapies.

Most patients were nulliparous in all groups. In the oocyte or tissue cryopreservation groups, 64 patients (88.9\%) were nulliparous, and 8 (11.1\%) had already given birth. In the GnRHa only group, nulliparous and parous patients were 94 (69.6\%) and 41 (30.4\%) respectively $(p=.002)$.

Most patients were high school graduates $(56.0 \%$ in the GnRHa, $34.6 \%$ in the $\mathrm{GnRHa}$ and oocyte cryopreservation, $58.8 \%$ in the GnRHa and tissue cryopreservation, and $45.7 \%$ in the no FP group) or college graduates (31.9\%, $61.5 \%, 23.5 \%$ and $42.9 \%$ respectively). Patients had intellectual or technical jobs (53.4\%, 48.1\%, 32.3\% and $55.9 \%$ respectively), unskilled jobs $(20.7 \%, 18.5 \%, 12.9 \%$ and $17.6 \%$ respectively) or were students $(23.3 \%, 29.6 \%, 48.4 \%$ and $17.6 \%$ respectively).

Hodgkin lymphoma $(\mathrm{HL})$ accounted for most cases in all groups [65 patients (48.1\%) in the GnRHa only group, 15 (48.4\%) in the $\mathrm{GnRHa}$ and oocyte group, and 26 (63.4\%) in the GnRHa and tissue cryopreservation group], followed by NHL (32 [23.7\%], 5 [16.1\%] and 5 [12.2\%] respectively) and breast cancer (9 [14.1\%], 8 [25.8\%] and 2 [4.9\%]). As first-line treatment, nearly $40 \%$ of patients $(n=101)$ in all groups underwent radiotherapy and almost all received CTh. Forty-five patients received HSCT.

The median time from GD referral to oocyte retrieval was 11 days (range: 1-35). The median time for laparoscopic surgery for ovarian tissue cryopreservation was five days (range: 1-22). Five patients underwent tissue cryopreservation laparoscopy after low-risk chemotherapy and before HSCT.

Patients were given follow-up appointments 1, 6, 12, 24 and 36 months after completion of CTh for gynaecological examination, review of clinical history, pelvic ultrasound scan with antral follicular count and endometrial thickness, and blood tests for hormonal profiling.

$\mathrm{AMH}, \mathrm{FSH}$ and $17 \beta \mathrm{e}$ levels at baseline and during the follow-up visits are presented in Table 2 and showed in Figure 1.

Cross-sectional results are shown in Table 2 for the follicular, ovulation and luteal phase; no statistical association was observed between baseline AMH levels and menstrual cycle phase $(p=.25)$, while median FSH and 17 pe levels were statistically significantly higher in the follicular phase for FSH $(p<.0001)$ and in ovulation phase for $17 \beta \mathrm{e}(p<.0001)$.

Seven patients had post-treatment pregnancies, all of which occurred spontaneously. Of these, three patients were treated with ABVD for $\mathrm{HL}$, one with RCHOP for NHL, one with EC and Taxol for breast cancer, one with just tamoxifen for breast cancer (suspended after two years of treatment to achieve a pregnancy). One patient was not treated with CTh but underwent an ovariectomy 
TAB LE 2 AMH, FSH and 17BE levels at baseline (overall and according to the menstrual cycle phase) and during the follow-up visits

\begin{tabular}{|c|c|c|c|c|c|c|}
\hline & $\begin{array}{l}\text { TO }(n=219) \text { median } \\
\text { (range) }\end{array}$ & $\begin{array}{l}\text { T1 ( } n=64) \text { me- } \\
\text { dian (range) }\end{array}$ & $\begin{array}{l}\text { T6 ( } n=27) \text { me- } \\
\text { dian (range) }\end{array}$ & $\begin{array}{l}\text { T12 ( } n=21) \text { me- } \\
\text { dian (range) }\end{array}$ & $\begin{array}{l}\text { T24 ( } n=18 \text { ) me- } \\
\text { dian (range) }\end{array}$ & $\begin{array}{l}\text { T36 }(n=9) \text { me- } \\
\text { dian (range) }\end{array}$ \\
\hline \multicolumn{7}{|l|}{ AMH } \\
\hline Follicular & $2.1(0.1-16.0)$ & & & & & \\
\hline Ovulation & $2.9(0.5-7.1$ & & & & & \\
\hline \multicolumn{7}{|l|}{ FSH } \\
\hline Overall & $5.7(0.1-147)$ & $8.1(0.3-194.93)$ & $8.9(0.24-171.1)$ & $12.4(0.6-115.3)$ & $12.8(4.3-132.8)$ & $10.5(4.2-123.9)$ \\
\hline Follicular & $6.6(1.6-23.9)$ & & & & & \\
\hline Ovulation & $4.3(0.1-14.0)$ & & & & & \\
\hline Luteal & $4.1(0.7-52.6)$ & & & & & \\
\hline Follicular & $50.5(0.02-323.0)$ & & & & & \\
\hline Ovulation & $132(11-348)$ & & & & & \\
\hline Luteal & $104(1.5-384)$ & & & & & \\
\hline
\end{tabular}

Abbreviations: $\mathrm{AMH}$, anti-müllerian hormone; FSH, follicle-stimulating hormone.
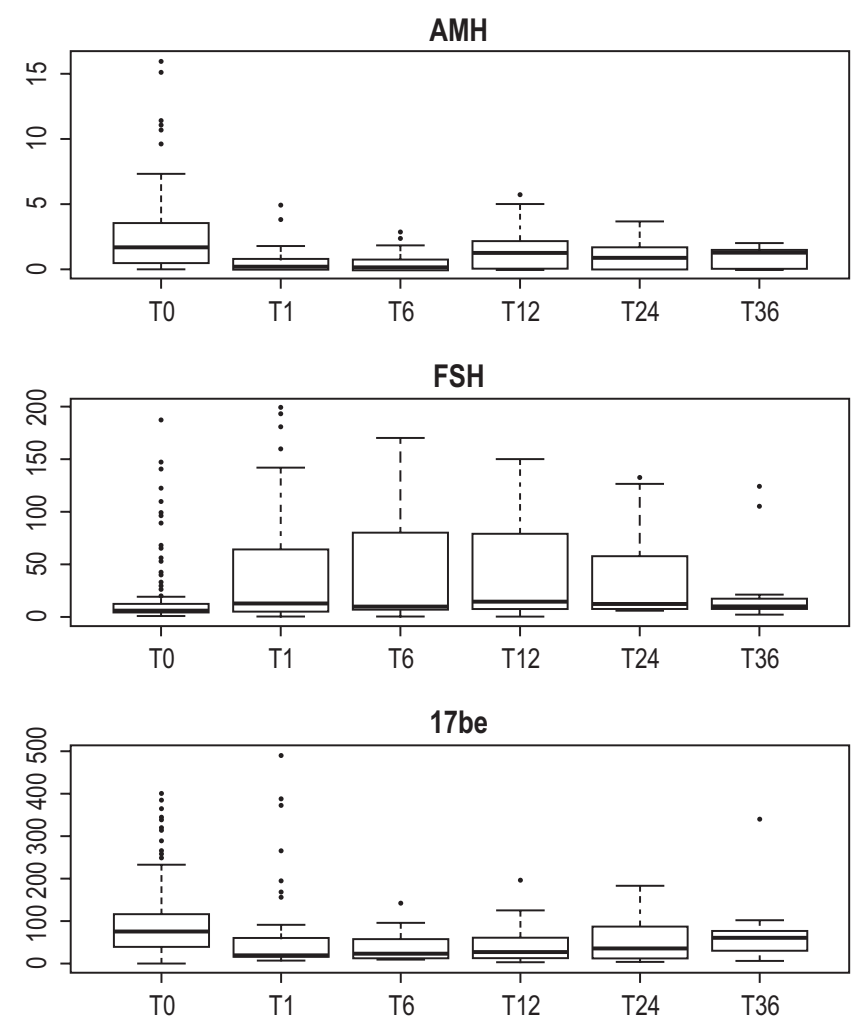

FIGURE 1 Boxplot of anti-müllerian hormone, folliclestimulating hormone and $17 \mathrm{BE}$ levels at baseline and during the follow-up visits

for a Granulosa cell neoplasm. Two of them performed ovarian tissue cryopreservation but did not re-implant the tissue, whereas all the patients who underwent CTh were co-treated with GnRHa. We registered six live births with healthy babies and one first-trimester miscarriage.

\section{DISCUSSION}

FP care (GnRHa and/or cryopreservation of ovarian tissue and oocytes) must be personalised and specific for each patient. Ovarian tissue cryopreservation is still considered an experimental procedure but presents several advantages, namely the possibility to start chemotherapy immediately after surgery and a wider range of eligible candidates, which includes pre-pubertal patients. The number of pregnancies after autotransplantation of cryopreserved ovarian tissue is growing fast (Meirow et al., 2016; Van der Ven et al., 2016). It was recently reported that, worldwide, almost 100 children have been conceived following transplantation of frozen-thawed ovarian tissue (89 successful births and nine ongoing pregnancies at the time of manuscript writing) (Donnez \& Dolmans, 2017; Jensen et al., 2017). Ovarian tissue cryopreservation is aimed not only at preserving fertility in cancer survivors but also ovarian function, which has been compromised by cancer therapies. Although a useful strategy, ovarian tissue cryopreservation presents some limitations, namely the concern of reseeding cancer cells during ovarian transplantation. The risk of re-introducing cancer cells after re-implantation depends on the type of tumour and ranges from low $(<0.2 \%)$ to high ( $>11 \%)$. Indeed, while ovarian involvement is rare in some tumours, systemic cancers, such as aggressive leukaemia, pose a higher risk (Oktay, 2001). However, recent studies have shown that it is possible to safely re-implant ovarian tissue in cancer patients, including leukaemia survivors, if appropriate precautions are taken and preliminary 
examinations on the tissue performed (Ben-Aharon et al.., 2016; Meirow et al., 2016).

Oocyte cryopreservation is considered a standard FP option but is not suitable for pre-pubertal girls and, due to the need for COS, cannot be used when therapy must be urgently started. In addition, some precautions must be taken in the case of patients with hormone-sensitive tumours.

All eligible patients enrolled in our study were offered at least one FP option. Patients who underwent neither oocyte nor ovarian tissue cryopreservation were significantly older than the others.

Most patients were nulliparous in all groups, and a significantly higher number of these patients chose to undergo cryopreservation of oocytes or tissue, whereas most women who had given birth before were treated with GnRHa only $(p=.002)$.

Hodgkin lymphoma $(\mathrm{HL})$ accounted for most cases in all groups, followed by NHL and breast cancer due to the high rate of long-term survival of patients with $\mathrm{HL}$ and a more intensive collaboration between GD and the Lymphoma Lazio District.

Blood test monitoring was used as a first evaluation of postchemotherapy hormonal activity. At follow-up (1, 6, 12, 24 and 36 months after the completion of CTh treatment), $17 \beta$-estradiol and FSH levels were significantly increased $(p<.0001)$, while a statistically significant decrease was observed for AMH levels $(p<.0001)$. As blood tests at baseline were performed randomly, cross-sectional results were given for the follicular, ovulatory and luteal phase; no statistical association was observed between baseline $\mathrm{AMH}$ levels and menstrual cycle phase $(p=.25)$ (Fréour, Barrière, \& Masson, 2017; Iwase, Nakamura, Nakahara, Goto, \& Kikkawa, 2015), while median FSH and $17 \beta$ e levels were statistically significantly higher in the follicular phase for FSH $(p<.0001)$ and in the ovulation phase for $17 \beta \mathrm{e}(p<.0001)$.

The incidence rate of pregnancies and live births from GD's FP programme is still not available for most patients due to the duration of the follow-up, since an average observation of 3-5 years is required for the diseases considered in the present paper.

Recent studies highlighted the importance of FP counselling (Deshpande et al., 2015), presence of a psychologist (Razzano et al., 2014) and improved education for healthcare teams (Diesch et al., 2017) in reducing dissatisfaction concerning fertility, and improving physical/psychological QoL.

In our experience, most patients benefited from the GD's FP programme since they underwent procedures that contributed to fertility preservation and future pregnancies. Cryopreservation was not performed in a subgroup of eligible patients, as almost $1 / 3$ of these patients refused the procedure for personal choice (Jones et al., 2017). For this reason, GD asked all patients $>18$ years to fill out four validated psychological questionnaires at baseline and during follow-up and offered psychological support during and after treatment, both for patients undergoing FP treatments and those who refused treatment. The analysis of this psychological survey will be the object of further investigations.

Our preliminary results are supported by several studies showing that patients who receive specialised counselling about reproductive loss and pursue fertility preservation have a better quality of life. Women suffering from gynaecological tumours may also be eligible for fertility-sparing surgery that can preserve their reproductive potential (Chiofalo et al., 2017; Vitale, Rossetti, Tropea, Biondi, \& Laganà, 2017). Therefore, it is important to provide complete information about fertility preservation options and to transform patients into active decision-makers in the treatment process (Laganà, Rosa, Rapisarda, Platania, \& Vitale, 2017; Letourneau et al., 2012; Vitale, Rosa, Rapisarda, \& Laganà, 2018).

GD's FP programme is free, effective and standardised according to international guidelines (Dalle et al., 2017; Font-Gonzalez et al., 2016; Lewin et al., 2017). Because of the lack of a systematic FP programme in most regions in Italy, GD's network aims to promote a valid model for FP counselling, assessment and treatment that could improve the NHS's FP care currently offered to young cancer patients (Quinn et al., 2016). We believe that our effort put in informing oncologists, haematologists, paediatricians and other specialists on FP care resulted in an active network, and a well-designed FP programme that is able to provide a high-quality service to young patients in need of better FP care.

\section{ACKNOWLEDGEMENTS}

The authors would like to thank OPM (Otto Per Mille) Chiesa Evangelica Valdese for its unconditional financial support to the organisation which contributed to making this work possible. The authors would also like to thank Alfonso Piciocchi for the work with the statistical analysis.

\section{CONFLICTS OF INTEREST}

The authors indicate no potential conflicts of interest.

\section{ORCID}

Mariavita Ciccarone (iD https://orcid.org/0000-0003-0235-5684

\section{REFERENCES}

AIOM (2016). Linee guida Preservazione della fertilità nei pazienti oncologici. AIOM.

Allen, P. B., Pavone, M. E., Smith, K. N., Kazer, R. R., Rademaker, A., Lawson, A. K., ... Winter, J. N. (2018). The impact of fertility preservation on treatment delay and progression-free survival in women with lymphoma: A single-centre experience. British Journal of Haematology, 180(6), 901-904. https://doi.org/10.1111/bjh.14466

Behringer, K., Thielen, I., Mueller, H., Goergen, H., Eibl, A. D., Rosenbrock, J., ... Borchmann, P. (2012). Fertility and gonadal function in female survivors after treatment of early unfavorable Hodgkin lymphoma $(\mathrm{HL})$ within the German Hodgkin Study Group HD14 trial. Annals of Oncology: Official Journal of the European Society for Medical Oncology, 23(7), 1818-1825. https://doi. org/10.1093/annonc/mdr575

Ben-Aharon, I., Abir, R., Perl, G., Stein, J., Gilad, G., Toledano, H., ... Ash, S. (2016). Optimizing the process of fertility preservation in pediatric 
female cancer patients - A multidisciplinary program. BMC Cancer, 16, 620. https://doi.org/10.1186/s12885-016-2584-7

Blumenfeld, Z. (2016). Critical care for young women before chemotherapy: Preserving fertility using GnRH agonists. Critical Care Obstetrics and Gynecology, 2, 16.

Blumenfeld, Z., \& Evron, A. (2016). Endocrine prevention of chemotherapy-induced ovarian failure. Current Opinion in Obstetrics and Gynecology, 28(4), 223-229. https://doi.org/10.1097/GCO.00000 00000000278

Blumenfeld, Z., Zur, H., \& Dann, E. J. (2015). Gonadotropin-releasing hormone agonist cotreatment during chemotherapy may increase pregnancy rate in survivors. The Oncologist, 20(11), 1283-1289. https:// doi.org/10.1634/theoncologist.2015-0223

Cakmak, H., \& Rosen, M. P. (2013). Ovarian stimulation in cancer patients. Fertility and Sterility, 99(6), 1476-1484. https://doi.org/10.1016/j. fertnstert.2013.03.029

Cao, Y.-X., \& Chian, R.-C. (2009). Fertility preservation with immature and in vitro matured oocytes. Seminars in Reproductive Medicine, 27(6), 456-464. https://doi.org/10.1055/s-0029-1241055

Chiofalo, B., Palmara, V., Laganà, A. S., Triolo, O., Vitale, S. G., Conway, F., \& Santoro, G. (2017). Fertility sparing strategies in patients affected by placental site trophoblastic tumor. Current Treatment Options in Oncology, 18(10), 58. https://doi.org/10.1007/s11864-017-0502-0

Dalle, J.-H., Lucchini, G., Balduzzi, A., Ifversen, M., Jahnukainen, K., Macklon, K. T., ... Bader, P. (2017). State-of-the-art fertility preservation in children and adolescents undergoing haematopoietic stem cell transplantation: A report on the expert meeting of the Paediatric Diseases Working Party (PDWP) of the European Society for Blood and Marrow Transplantation (EBMT) in Baden, Austria, 29-30 September 2015. Bone Marrow Transplantation, 52(7), 1029-1035. https://doi.org/10.1038/bmt.2017.21

Del Mastro, L., Boni, L., Michelotti, A., Gamucci, T., Olmeo, N., Gori, S., .. Venturini, M. (2011). Effect of the gonadotropin-releasing hormone analogue triptorelin on the occurrence of chemotherapy-induced early menopause in premenopausal women with breast cancer: $A$ randomized trial. JAMA, 306(3), 269-276. https://doi.org/10.1001/ jama.2011.991

Del Mastro, L., Ceppi, M., Poggio, F., Bighin, C., Peccatori, F., Demeestere, I., ... Bruzzi, P. (2014). Gonadotropin-releasing hormone analogues for the prevention of chemotherapy-induced premature ovarian failure in cancer women: Systematic review and meta-analysis of randomized trials. Cancer Treatment Reviews, 40(5), 675-683. https:// doi.org/10.1016/j.ctrv.2013.12.001

Demeestere, I., Brice, P., Peccatori, F. A., Kentos, A., Dupuis, J., Zachee, P., ... Englert, Y. (2016). No evidence for the benefit of gonadotropin-releasing hormone agonist in preserving ovarian function and fertility in lymphoma survivors treated with chemotherapy: final long-term report of a prospective randomized trial. Journal of Clinical Oncology: Official Journal of the American Society of Clinical Oncology, 34(22), 2568-2574. https://doi.org/10.1200/JCO.2015.65.8864

Deshpande, N. A., Braun, I. M., \& Meyer, F. L. (2015). Impact of fertility preservation counseling and treatment on psychological outcomes among women with cancer: A systematic review. Cancer, 121(22), 3938-3947. https://doi.org/10.1002/cncr.29637

Diesch, T., Rovo, A., von der Weid, N., Faraci, M., Pillon, M., Dalissier, A., ... Bader, P. (2017). Fertility preservation practices in pediatric and adolescent cancer patients undergoing HSCT in Europe: A population-based survey. Bone Marrow Transplantation, 52(7), 1022-1028. https://doi.org/10.1038/bmt.2016.363

Donnez, J., \& Dolmans, M.-M. (2017). Fertility preservation in women. New England Journal of Medicine, 377(17), 1657-1665. https://doi. org/10.1056/NEJMra1614676

Font-Gonzalez, A., Mulder, R. L., Loeffen, E. A. H., Byrne, J., van Dulmenden Broeder, E., van den Heuvel-Eibrink, M. M., ...PanCareLIFE Consortium (2016). Fertility preservation in children, adolescents, and young adults with cancer: Quality of clinical practice guidelines and variations in recommendations. Cancer, 122(14), 2216-2223. https://doi.org/10.1002/cncr.30047

Fréour, T., Barrière, P., \& Masson, D. (2017). Anti-müllerian hormone levels and evolution in women of reproductive age with breast cancer treated with chemotherapy. European Journal of Cancer, 74, 1-8. https://doi.org/10.1016/j.ejca.2016.12.008

Garrido-Oyarzun, M. F., \& Castelo-Branco, C. (2016). Controversies over the use of GnRH agonists for reduction of chemotherapyinduced gonadotoxicity. Climacteric, 19, 522-525. https://doi. org/10.1080/13697137.2016.1225713

Gracia, C. R., Sammel, M. D., Freeman, E., Prewitt, M., Carlson, C., Ray, A., ... Ginsberg, J. P. (2012). Impact of cancer therapies on ovarian reserve. Fertility and Sterility, 97(1), 134-140.e1. https://doi. org/10.1016/j.fertnstert.2011.10.040

Iwase, A., Nakamura, T., Nakahara, T., Goto, M., \& Kikkawa, F. (2015). Anti-Müllerian hormone and assessment of ovarian reserve after ovarian toxic treatment: A systematic narrative review. Reproductive Sciences, 22(5), 519-526. https://doi.org/10.1177/1933719114 549856

Jensen, A. K., Macklon, K. T., Fedder, J., Ernst, E., Humaidan, P., \& Andersen, C. Y. (2017). 86 successful births and 9 ongoing pregnancies worldwide in women transplanted with frozen-thawed ovarian tissue: Focus on birth and perinatal outcome in $\mathbf{4 0}$ of these children. Journal of Assisted Reproduction and Genetics, 34(3), 325-336. https ://doi.org/10.1007/s10815-016-0843-9

Jones, G., Hughes, J., Mahmoodi, N., Smith, E., Skull, J., \& Ledger, W. (2017). What factors hinder the decision-making process for women with cancer and contemplating fertility preservation treatment? Human Reproduction Update, 23(4), 433-457. https://doi. org/10.1093/humupd/dmx009

ISFP Practice Committee, Kim, S. S., Donnez, J., Barri, P., Pellicer, A., Patrizio, P., ... Dolmans, M.-M. (2012). Recommendations for fertility preservation in patients with lymphoma, leukemia, and breast cancer. Journal of Assisted Reproduction and Genetics, 29(6), 465-468. https://doi.org/10.1007/s10815-012-9786-y

Laganà, A. S., La Rosa, V. L., Rapisarda, A. M., Platania, A., \& Vitale, S. G. (2017). Psychological impact of fertility preservation techniques in women with gynaecological cancer. Ecancermedicalscience, 11, ed62. https://doi.org/10.3332/ecancer.2017.ed62

Lambertini, M., Boni, L., Michelotti, A., Gamucci, T., Olmeo, N., Gori, S., ... Del Mastro, L. (2014). Long-term outcome results of the phase III PROMISE-GIM6 study evaluating the role of LHRH analog (LHRHa) during chemotherapy (CT) as a strategy to reduce ovarian failure in early breast cancer (BC) patients. Journal of Clinical Oncology, 32(26_suppl), 105-105. https://doi.org/10.1200/ jco.2014.32.26_suppl.105

Lambertini, M., Ceppi, M., Poggio, F., Peccatori, F. A., Azim, H. A., Ugolini, D., ... Del Mastro, L. (2015). Ovarian suppression using luteinizing hormone-releasing hormone agonists during chemotherapy to preserve ovarian function and fertility of breast cancer patients: A metaanalysis of randomized studies. Annals of Oncology: Official Journal of the European Society for Medical Oncology, 26(12), 2408-2419. https ://doi.org/10.1093/annonc/mdv374

Lambertini, M., Cinquini, M., Moschetti, I., Peccatori, F. A., Anserini, P., Valenzano Menada, M., \& Del Mastro, L. (2017). Temporary ovarian suppression during chemotherapy to preserve ovarian function and fertility in breast cancer patients: A GRADE approach for evidence evaluation and recommendations by the Italian Association of Medical Oncology. European Journal of Cancer, 71, 25-33. https://doi. org/10.1016/j.ejca.2016.10.034

Lambertini, M., Del Mastro, L., Pescio, M. C., Andersen, C. Y., Azim, H. A., Peccatori, F. A., ... Anserini, P. (2016). Cancer and fertility preservation: International recommendations from an expert meeting. BMC Medicine, 14, 1. https://doi.org/10.1186/s12916-015-0545-7 
Lambertini, M., Ginsburg, E. S., \& Partridge, A. H. (2015). Update on fertility preservation in young women undergoing breast cancer and ovarian cancer therapy. Current Opinion in Obstetrics \& Gynecology, 27(1), 98-107. https://doi.org/10.1097/GCO.0000000000000138

Lambertini, M., Horicks, F., Del Mastro, L., Partridge, A. H., \& Demeestere, I. (2019). Ovarian protection with gonadotropin-releasing hormone agonists during chemotherapy in cancer patients: From biological evidence to clinical application. Cancer Treatment Reviews, 72, 65-77. https://doi.org/10.1016/j.ctrv.2018.11.006

Lawson, A. K., Klock, S. C., Pavone, M. E., Hirshfeld-Cytron, J., Smith, K. N., \& Kazer, R. R. (2014). Prospective study of depression and anxiety in female fertility preservation and infertility patients. Fertility and Sterility, 102(5), 1377-1384. https://doi.org/10.1016/j.fertn stert.2014.07.765

Letourneau, J. M., Ebbel, E. E., Katz, P. P., Katz, A., Ai, W. Z., Chien, A. J., ... Rosen, M. P. (2012). Pretreatment fertility counseling and fertility preservation improve quality of life in reproductive age women with cancer. Cancer, 118(6), 1710-1717. https://doi.org/10.1002/ cncr.26459

Lewin, J., Ma, J. M. Z., Mitchell, L., Tam, S., Puri, N., Stephens, D., ... Gupta, A. (2017). The positive effect of a dedicated adolescent and young adult fertility program on the rates of documentation of therapy-associated infertility risk and fertility preservation options. Supportive Care in Cancer: Official Journal of the Multinational Association of Supportive Care in Cancer, 25(6), 1915-1922. https:// doi.org/10.1007/s00520-017-3597-8

Loren, A. W., Mangu, P. B., Beck, L. N., Brennan, L., Magdalinski, A. J., \& Partridge, A. H., ...American Society of Clinical Oncology (2013). Fertility preservation for patients with cancer: American Society of Clinical Oncology clinical practice guideline update. Journal of Clinical Oncology: Official Journal of the American Society of Clinical Oncology, 31(19), 2500-2510. https://doi.org/10.1200/JCO.2013.49.2678

Meirow, D., Ra'anani, H., Shapira, M., Brenghausen, M., Derech Chaim, S., Aviel-Ronen, S., ... Dor, J. (2016). Transplantations of frozen-thawed ovarian tissue demonstrate high reproductive performance and the need to revise restrictive criteria. Fertility and Sterility, 106(2), 467474. https://doi.org/10.1016/j.fertnstert.2016.04.031

Moore, H. C. F., Unger, J. M., Phillips, K.-A., Boyle, F., Hitre, E., Porter, D. ... Albain, K. S. (2015). Goserelin for ovarian protection during breastcancer adjuvant chemotherapy. The New England Journal of Medicine, 372(10), 923-932. https://doi.org/10.1056/NEJMoa1413204

Moravek, M. B., Confino, R., Smith, K. N., Kazer, R. R., Klock, S. C., Lawson, A. K., ... Pavone, M. E. (2018). Long-term outcomes in cancer patients who did or did not pursue fertility preservation. Fertility and Sterility, 109(2), 349-355. https://doi.org/10.1016/j.fertnstert.2017.10.029

Oktay, K. (2001). Ovarian tissue cryopreservation and transplantation: Preliminary findings and implications for cancer patients. Human Reproduction, 7(6), 526-534. https://doi.org/10.1093/humup $\mathrm{d} / 7.6 .526$

Oktay, K., Demirtas, E., Son, W.-Y., Lostritto, K., Chian, R.-C., \& Tan, S. L. (2008). In vitro maturation of germinal vesicle oocytes recovered after premature luteinizing hormone surge: Description of a novel approach to fertility preservation. Fertility and Sterility, 89(1), 228. e19-228.e22. https://doi.org/10.1016/j.fertnstert.2007.02.028

Partridge, A. H., Gelber, S., Peppercorn, J., Sampson, E., Knudsen, K., Laufer, M., ... Winer, E. P. (2004). Web-based survey of fertility issues in young women with breast cancer. Journal of Clinical Oncology: Official Journal of the American Society of Clinical Oncology, 22(20), 4174-4183. https://doi.org/10.1200/JCO.2004.01.159

Peccatori, F. A., Azim, H. A., Orecchia, R., Hoekstra, H. J., Pavlidis, N., \& Kesic, V., ...ESMO Guidelines Working Group. (2013). Cancer, pregnancy and fertility: ESMO Clinical Practice Guidelines for diagnosis, treatment and follow-up. Annals of Oncology: Official Journal of the European Society for Medical Oncology, 24 Suppl 6, vi160-170. https:// doi.org/10.1093/annonc/mdt199
Practice Committee of American Society for Reproductive Medicine (2013). Fertility preservation in patients undergoing gonadotoxic therapy or gonadectomy: A committee opinion. Fertility and Sterility, 100(5), 1214-1223. https://doi.org/10.1016/j.fertn stert.2013.08.012

Quinn, G. P., Woodruff, T. K., Knapp, C. A., Bowman, M. L., Reinecke, J., \& Vadaparampil, S. T. (2016). Expanding the oncofertility workforce: Training allied health professionals to improve health outcomes for adolescents and young adults. Journal of Adolescent and Young Adult Oncology, 5(3), 292-296. https://doi.org/10.1089/ jayao.2016.0003

Razzano, A., Revelli, A., Delle Piane, L., Salvagno, F., Casano, S., Randaccio, S., \& Benedetto, C. (2014). Fertility preservation program before ovarotoxic oncostatic treatments: Role of the psychological support in managing emotional aspects. Gynecological Endocrinology: The Official Journal of the International Society of Gynecological Endocrinology, 30(11), 822-824. https://doi.org/10.3109/09513 590.2014 .944153

Ruddy, K. J., Gelber, S. I., Tamimi, R. M., Ginsburg, E. S., Schapira, L., Come, S. E., ... Partridge, A. H. (2014). Prospective study of fertility concerns and preservation strategies in young women with breast cancer. Journal of Clinical Oncology: Official Journal of the American Society of Clinical Oncology, 32(11), 1151-1156. https://doi. org/10.1200/JCO.2013.52.8877

Salama, M., Isachenko, V., Isachenko, E., Rahimi, G., \& Mallmann, P. (2016). Updates in preserving reproductive potential of prepubertal girls with cancer: Systematic review. Critical Reviews in Oncology/Hematology, 103, 10-21. https://doi.org/10.1016/j.critr evonc.2016.04.002

Siegel, R. L., Miller, K. D., \& Jemal, A. (2017). Cancer Statistics, 2017. CA: A Cancer Journal for Clinicians, 67(1), 7-30. https://doi.org/10.3322/ caac. 21387

Sigismondi, C., Papaleo, E., Vigano, P., Vailati, S., Candiani, M., Ottolina, J., ... Mangili, G. (2015). Fertility preservation in female cancer patients: A single center experience. Chinese Journal of Cancer, 34(1), 56-60. https://doi.org/10.5732/cjc.014.10252

Stensheim, H., Cvancarova, M., Møller, B., \& Fosså, S. D. (2011). Pregnancy after adolescent and adult cancer: A population-based matched cohort study. International Journal of Cancer, 129(5), 1225-1236. https ://doi.org/10.1002/ijc. 26045

Tavares, R. L., Senra, J. C., Talim, M. C., \& Reis, F. M. (2016). Fertility preservation with the use of $\mathrm{GnRH}$ analogue in women undergoing chemotherapy for lymphoma: A systematic review and meta-analysis. Fertility and Sterility, 106(3), e133. https://doi.org/10.1016/j.fertn stert.2016.07.396

Van der Ven, H., Liebenthron, J., Beckmann, M., Toth, B., Korell, M., Krüssel, J., ... Dittrich, R. (2016). Ninety-five orthotopic transplantations in 74 women of ovarian tissue after cytotoxic treatment in a fertility preservation network: Tissue activity, pregnancy and delivery rates. Human Reproduction, 31(9), 2031-2041. https://doi. org/10.1093/humrep/dew165

Vitale, S. G., La Rosa, V. L., Rapisarda, A. M. C., \& Laganà, A. S. (2018). Fertility preservation in women with gynaecologic cancer: The impact on quality of life and psychological well-being. Human Fertility, 21(1), 35-38. https://doi.org/10.1080/14647273.2017.1339365

Vitale, S. G., Rossetti, D., Tropea, A., Biondi, A., \& Laganà, A. S. (2017). Fertility sparing surgery for stage IA type I and G2 endometrial cancer in reproductive-aged patients: Evidence-based approach and future perspectives. Updates in Surgery, 69(1), 29-34. https://doi. org/10.1007/s13304-017-0419-y

Vu, J. V., Llarena, N. C., Estevez, S. L., Moravek, M. B., \& Jeruss, J. S. (2017). Oncofertility program implementation increases access to fertility preservation options and assisted reproductive procedures for breast cancer patients. Journal of Surgical Oncology, 115(2), 116121. https://doi.org/10.1002/jso. 24418 
Wong, M., O'Neill, S., Walsh, G., \& Smith, I. E. (2013). Goserelin with chemotherapy to preserve ovarian function in pre-menopausal women with early breast cancer: Menstruation and pregnancy outcomes. Annals of Oncology: Official Journal of the European Society for Medical Oncology, 24(1), 133-138. https://doi.org/10.1093/ annonc/mds 250
How to cite this article: Ciccarone M, Hohaus S, Pulsoni A, et al. Preliminary results of a counselling programme for fertility preservation in female cancer patients: The experience of the GEMME DORMIENTI network. Eur J Cancer Care.

2019;00:e13174. https://doi.org/10.1111/ecc.13174 